Bol. Acad. peru. leng. 54. 2012 (63-85)

\title{
POESÍA DE LOS DESCENDIENTES DE ÁRABES ('NEOMAHYARÍ') EN AMÉRICA LATINA*
}

\author{
POESIE DES DESCENDENTS DES ARABES \\ ('NEOMAHYARÍ') EN AMÉRIQUE LATINE*
}

\section{POETRY OF DESCENDANTS OF ARABS IN LATIN AMERICA*}

\author{
María Olga Samamé B. \\ Centro de Estudios Árabes \\ Universidad de Chile
}

\section{Resumen:}

La emigración árabe en las Américas se inició a finales del siglo XIX, y fue motivada por diversos factores negativos debido a la dominación turco-otomana y el colonialismo europeo en el Medio Oriente. Cabe señalar que, entre los árabes llegados al Nuevo Mundo, se destacaron algunos intelectuales pioneros, quienes fundaron asociaciones literarias y estimularon en sus descendientes la permanencia de una particular conciencia colectiva de su origen árabe. Los talentos literarios comenzaron a expresarse en la segunda y tercera generación de descendientes de inmigrantes, y continúa en el presente. Surge una literatura en la cual prevaleció el anhelo de preservar los valores de la cultura árabe y de mantener viva la memoria de sus antepasados, durante el proceso de

* Ponencia presentada en el Congreso Internacional Poesía Hispanoamericana: de la Vanguardia a la Posmodernidad, realizado del 23 al 25 de abril de 2012. 
integración en el país de acogida. Así, desarraigo, añoranza, marginación, adaptación, inserción e integración constituyen, en su conjunto, los cimientos de la inmigración árabe en las Américas y han inspirado la forma "neomahyarí" o literatura creada por algunos escritores hijos de los inmigrantes, y cuyas obras líricas (y también narrativas) conllevan la triple impronta de la nostalgia, el pensamiento y la libertad.

\section{Résumé:}

L'émigration arabe aux Amériques a commencé à la fin du XIX siècle, et a été motivée par des différents facteurs négatifs dû à la domination turcottomane et le colonialisme européen au Moyen Orient. Il faut signaler que, entre les arabes arrivés au Nouveau Monde, se sont remarqués quelques intellectuels pionniers, qui ont fondé des associations littéraires et on stimulé leurs descendantes la permanence d'une particulière conscience collective de son origine arabe. Les talents littéraires ont commencé à s'exprimer dans la deuxième et troisième génération de descendantes d'immigrants, et continue jusqu'au présent. Emerge une littérature dans laquelle a prévalu l'anhèle de préserver les valeurs de la culture arabe et de maintenir vivante la mémoire de leurs ancêtres, durant le processus d'intégration dans le pays d'accueil. Ainsi, déracinement, nostalgie, marginassion, adaptation, insertion et intégration constituent, dans son ensemble, les fondements de l'immigration arabe aux Amériques et ont inspiré la forme "neomahyarí" ou littérature crée par quelques écrivains fils des immigrants, et dont les ouvrages lyriques (et narratives aussi) entraînent la triple empreinte de la nostalgie, la pensée et la liberté.

\section{Abstract:}

Arab emigration to American countries began at the end of the ninetenth century and was undertaken as the result of different negative factors due to Ottoman Turkish domination and European colonization in the Middle East. It is worth noting that among the Arabs who arrived at the New World there were intellectual pioneers who founded literary associations and stimulated the permanence of a special kind of collective Arab origin among their descendants. Literary talent began to manifest itself among the second and third generation of descendants of immigrants and continues to the present. A literature springs up in 
which the aim to preserve the values of Arabian culture and keep the memory of ancestors alive during a process of integration in the adopted country has prevailed. In this manner a sense of rootlessnes, nostalgia, social prejudice, adaptation and problems of custom, insertion and integration as well, lie at the base of Arab immigration into American countries and have inspired a form called "neomahyari" that is literature created by some writers who are in fact the sons of immigrants, and whose lyrical (and also narrative) production bring together the triple impression of longing for home, serious thought and liberty.

Palabras clave: inmigración árabe, cultura árabe, neomahyarí.

Mots clés: immigration arabe, culture arabe, néomahdjar.

Key words: Arabic immigration, Arabic culture, neomahyarí.

Fecha de recepción: $\quad$ 25/04/2012

Fecha de aceptación: $\quad$ 10/10/2012

Una modalidad de recuperación del pasado para revivirlo y reconstruirlo ha sido escribir inevitablemente desde la memoria. La escritura retrospectiva, esa mirada hacia atrás en la ficción, está animada por la necesidad de rescatar, entender y comprender instancias pretéritas. Se trata de una escritura a veces plena de dinamismo y creatividad lúdicas; otras veces cuestionadora y rebelde. Asimismo, es una rememoración escritural, interpretativa, valorativa, perspectivista e, incluso, impugnadora, en cuanto vuelve a fundar y a legitimar el objeto evocado. En esta dimensión se inserta el tema de la producción literaria de algunos escritores de origen árabe en América Latina. Aun cuando en su mayoría no han conservado en esta escritura la seña de identidad del arabismo, esto es, la lengua árabe, y que pueda definirlos y particularizarlos, heredaron de sus padres, en cambio, una particular conciencia colectiva de ser árabes y poseedores de una patria espiritual y emotiva.

En efecto, durante el proceso de inserción, integración y asimilación en la tierra de acogida, los antepasados inmigrantes de la Gran Siria 
— hoy Siria, Palestina, el Líbano y Jordania — sobrellevaron la afirmación de su identidad diferenciada y, al mismo tiempo, fomentaron en sus descendientes el uso del español, para así facilitarles una expedita integración, quedando reducida la lengua árabe al ámbito familiar. La mayoría de estos escritores descendientes de la tierra levantina sienten que son poseedores de una doble identidad: una local, por nacimiento, educación, trabajo y desarrollo personal; otra árabe, porque conservan con emoción y respeto las tradiciones identitarias de sus antepasados.

Precisamente es esta identidad emotiva y atávica la que pervive en el imaginario de algunos escritores descendientes de árabes. Su cosmos escritural emerge de la afirmación de esta arabidad, en la cual se legitima su peculiar percepción de la tierra ancestral, al conservar una parte de las huellas identitarias tradicionales, culturales e históricas de la Gran Siria; asimismo, este cosmos queda conjugado holísticamente en un lento y sostenido proceso de reflexión y de recreación interpretativa. Sin duda, cada uno de estos escritores obtuvo experiencia directa de su familia y amigos emigrados y transplantados en cada nación de acogida; fueron testigos silentes de este grupo humano que cargaba dolorosamente en su cuerpo y alma el sentimiento de haber sido extraños en su propia tierra, sometida primero a la dominación turco-otomana, luego al colonialismo europeo para, más tarde, soportar, en algunos casos, la bipartición y la creación del Estado de Israel. Efectivamente, estos vates también escucharon nostalgias de la patria añorada, lejana e invadida, y del mismo modo comprobaron cómo los recuerdos compartidos de los emigrantes fortalecían la identidad grupal ancestral. Entonces, imbuidos por estos componentes pretéritos y vigentes y convencidos de que el pasado no se ha desvanecido, sino que permanece vivo en la memoria, la reconstruyen como un proyecto y deseo de continuidad, para integrarla en su producción literaria.

Cabe señalar que la intelectualidad descendiente se propone, de algún modo, recrear una producción escritural que había repercutido en el mundo árabe reconociéndosela como el "primer grande y auténtico movimiento de renovación de la poesía árabe moderna" . Se trata de Adab

1 MARTÍNEZ MONTÁVEZ 1974: 65. Capítulo IV: "Literatura del Mahyar". Se omiten los diacríticos árabes en el presente artículo. 
al-Mabyar — literalmente, Literatura de la Emigración, en América-, también denominada Al-Mahyar, la cual se originó en los Estados Unidos - en Boston y Nueva York-, con la obra de los poetas emigrados siriolibaneses, cuya principal y paradigmática figura fue Yibrán Jalil Yibrán² Al-Mahyar comprendió varios movimientos literarios: uno $A r$-rabita alQalamiyya, esto es, la Liga del Cálamo, fundado por Yubrán Jalil Yubrán y que se difundió en Brasil, Argentina y Chile ${ }^{3}$. Este movimiento creó una literatura con tendencias filosóficas, mitológicas, espirituales y sociales, innovando los metros y formas estróficas, con prosa poética o poesía prosificada, a veces de tono susurrado, con tendencia a lo bello y lo sublime, donde el tema de la nostalgia es fundamental. Otro movimiento literario fue Al Usba al-Andalusiyya o La Liga Andalusí, fundado en Brasil a comienzos del siglo XX y creado con el propósito de reivindicar la literatura de $\mathrm{Al}$ Andalus y, a través de ella, manifestar el ansia de libertad de sus países de origen, fomentar la hermandad entre los intelectuales árabes en América, combatir fanatismos e ideologías retrógradas. Finalmente, se destaca An-Nadwa Al-Adabiyya o Peñas Literarias, fundada en Brasil, Argentina y en Chile. En suma, los poetas del Mahyar ${ }^{4}$ conservaron y emplearon la lengua árabe en sus producciones; construyeron una escritura basada en experiencias personales; expresaron la nostalgia de la patria, el dolor social y colectivo

2 Yibrán Jalil Yibrán nació en la aldea libanesa de Bisharri en 1883, y falleció en Nueva York en 1931. Fue poeta, filósofo, ensayista y artista. Entre sus obras cabe señalar Espíritus rebeldes (1903); El profeta (1923); Jesús, el Hijo del Hombre (1928). Además de Yubrán Jalil Yubrán, integraron este movimiento Iliya Abu Madi (1889-1957), Mijail Nuayma (18891988), Amin ar-Rihani (1876-1940). En MARTÍNEZ LILLO 1994.

3 Motivado por este movimiento se creó en Sao Paulo, en 1933, con la fundación de $\mathrm{Al}$ Usba al-Andalusiyya, La Liga Andalusí; y en Buenos Aires, en 1947, con An-Nadwa alAdabiyya, La Peña Literaria. Está última entidad fue refundada en Chile, en 1955 . Véase AGAR 1997 y AGAR 2009.

4 La literatura de Al-Mahyar en las Américas produjo numerosos periódicos y revistas escritos en árabe y también bilingües. En Chile, por ejemplo, se fundaron los siguientes periódicos: al-Muř̌id (El Guía); Santiago, 7 de noviembre de 1912. Revista al-Awatif (Los Sentimientos); Santiago, 1 de diciembre de 1916. Periódico al-Munir (El Luminoso); Concepción, 21 de junio de 1916. Periódico al-Šabiba (La Juventud); Santiago, 1918. Periódico al-Wat.an (La Patria); Santiago, 15 de junio de 1920. Periódico al-Tafahum (La Armonía); Santiago, enero de 1923. Revista al-Šarq wa-l-Garb (Oriente y Occidente). Santiago, 15 de septiembre de 1923. Periódico al-Islah (La Reforma); Santiago, 1929.

Bol. Acad. peru. leng. 54(54), 2012 
con impronta metafísica, expresionista y simbolista occidental; tendieron hacia el Humanismo; se caracterizaron por el sentimiento profundo, por una naturaleza descriptiva e imaginativa, por un lirismo a veces quintaesenciado y porque se propusieron entregar un mensaje directo, personal, con libertad religiosa ${ }^{5}$ y con una defensa del nacionalismo por la patria usurpada y sometida. En el decir del arabista Pedro Martínez Montávez, esta "poesía neo-árabe se hace más humana, limpiamente asequible a cualquier hombre por encima de circunstancias, naturalezas y condiciones diversas" (Martínez Montávez 1974: 66).

Los escritores de las generaciones descendientes carecieron de la enseñanza sistemática del idioma vernacular y, por ende, escribieron sus obras ya sea en español o en portugués, según la lengua de la patria de acogida. A pesar de esta pérdida de la identidad y del uso de la lengua árabe, se percibe en los escritores descendientes el deseo de rescatar la memoria ancestral en un intento por reconstruir la historia de sus predecesores y descifrar la dicotomía presencia-ausencia como manifestación de quienes portan sobre sí dos escenarios: la patria ancestral y la patria de acogida. Así, se puede establecer que la escritura de la emigración árabe en América Latina llevada a cabo por algunos descendientes árabes se puede denominar "neomahyarí", pues también conlleva los principios orgánicos de la poesía del Mahyar, es decir, tiene la triple impronta de la nostalgia, del pensamiento y de la libertad ${ }^{6}$, conceptos que pueden traducirse en las siguientes modalidades: 1 . El tema de la nostalgia comprende el lamento y el recuerdo de la patria lejana (siria, libanesa y palestina), los seres

5 La mayoría de los inmigrantes eran de rito cristiano, maronita o melquita, pero sus tradiciones y costumbres se diferenciaban del rito latino. El rito melquita quiere decir 'imperiales'. La iglesia greco-católica melquita también conocida como iglesia católica greco-melquita es una iglesia oriental católica de rito bizantino (en su variante griega), es decir, es una iglesia particular de la Iglesia Católica que goza de autonomía y está en plena comunión con el papa de Roma. El clero melquita católico se forma principalmente en el Seminario de Santa Ana de Jerusalén, fundado en 1882 y encomendado a los Padres Blancos.

6 Señala Pedro Martínez Montávez (1974: 66) que la poesía del Mahyar ha sido estudiada por "muchos críticos modernos árabes", siendo uno de ellos Wadi Dib, quien la ha sistematizado en estos "tres esenciales". 
queridos y el deseo de retornar a ese espacio paradisíaco perdido para siempre, pero recuperable a través de la descripción de la naturaleza y el ejercicio de la memoria; 2 . El pensamiento, en tanto es un ámbito que adquiere instancias metafísicas, en las cuales proliferan indagaciones de respuestas insondables, a veces relacionadas con el cristianismo o con búsquedas metafísicas existenciales, o con mitologías; 3. El tópico de la libertad se vincula a la angustia del hombre al vivir este en un mundo deshumanizado y sin posibilidades de realizarse con plenitud e independencia, destacándose el hecho palestino y, por extensión, el anhelo libertario o el regreso de exiliados a su patria, sin obliterar el deseo de reivindicar la literatura de Al Andalus como un hito de pretérito espacio cultural y de libertad paradigmática que pueda fomentar la fraternidad entre los intelectuales árabes en América y combatir delirios e ideologías retrógradas ${ }^{7}$.

La lírica y la narrativa son todavía los vehículos de expresión de estos poetas "neomahyaríes" que se propusieron ser originales y representativos de una cultura geográficamente lejana, pero visibilizada. Asimismo, las proposiciones estéticas realistas y simbolistas de algunos de ellos se enmarcan dentro de los sistemas generacionales a los cuales pertenecen. A continuación se presenta un corpus de poetas seleccionado, no exhaustivo:

En Argentina se destacan dos escritoras neomahyaríes: la salteña Juana $\mathrm{Dib}^{8}$, en cuyo soneto seleccionado se cantan descripciones de lecturas milyunichescas, combinadas con espacios quebrantados por la guerra y la emoción:

7 Algunos poetas mahyaríes dedicaron al último baluarte arábigoandalus, Granada, composiciones donde esta ciudad surge victoriosa y derrotada, ganada y perdida. El imaginario árabe, a la postre, pretende significar que Granada es una realidad inconclusa.

8 Nació en Salta (Argentina), en 1924. Además de poetisa, es profesora y pertenece al Centro Salteño de Investigaciones de la Cultura Árabe. Ha recibido numerosos premios de instituciones de su ciudad natal y ha sido galardonada por diversas organizaciones árabes nacionales y extranjeras, y gran parte de su producción fue traducida y publicada en el Mundo Árabe. El poema aquí citado pertenece al poemario Las Doradas (1989).

Bol. Acad. peru. leng. 54(54), 2012 


\section{En la noche de Oriente}

De noche y día brilla un diamante a mi puerta, no sé si es una estrella, siempre está iluminada; no sé si es un candil que señala la entrada de que mi voz recita aún la rima desierta.

Por eso yo declamo: mi voz es una huerta, en ella están los trinos de la tarde aromada, en ella está el rocío de la luz de madrugada vestido de azucena con su diadema abierta.

Si una doncella sueña en la noche de Oriente, si escucha en el jardín que ilumina la fuente la estrella que destella, es que me dio su amado.

También hermanos canto las loas de la lucha, es cuando mi voz quiebra porque su endecha es mucha.

Si hasta la luna enluta con su rostro opacado.

La escritora argentina de la provincia de Río Negro, Ester Faride Matar", en su poema "Mis abuelos... los tuyos", concentra la triple impronta de la nostalgia, la memoria, la integración y el nacionalismo:

Llegaron de lejos masticando recuerdos, escapando de guerras con sed de justicia, $\tan$ solos... $\tan$ pobres...

9 Nació en la provincia de Río Negro (Argentina) y es autora de libros de poesías y narrativa. Pertenece a varias organizaciones literarias: el Foro de Escritores de la Región Sur de la Provincia de Río Negro, el movimiento Poetas del Mundo, el grupo Pluma y Palabra, el grupo Poesías y Reflexiones, el Portal Mundo Poesías, Grandes Poetas del Mundo, La Voz de la Palabra Escrita Internacional, entre otras. Algunas de sus publicaciones son: Desde el corazón, De eso se trata, Cuentos que no son cuentos. Véase su página personal en la web: http://www.esterfaridematar.com.ar/poema_abuelos.html 
Hicieron camino, unieron familia, buscaron trabajo, vendieron de todo, llevando en su alma un sentimiento fuerte de orgullo oriental en suelo argentino.

Recorrieron huellas, senderos de piedra, con frío, calor, viento y sudestada forjó su destino aquel inmigrante, con fuertes principios de libertad y coraje.

Mis abuelos... los tuyos, con distinto idioma no olvidaron su cuna, el café, el incienso y el cobre y en medio de campos, soledad y miedo gritaron un día: HERMANO ARGENTINO.

En Brasil proliferó una pléyade de intelectuales inmigrantes siriolibanesa como fue la dinastía de los Ma'aluf ${ }^{10}$, auténticos representantes del mahyarí brasileño. En la generación siguiente se distingue el poeta y periodista Asís Féres ${ }^{11}$ (1912-1978), que dedica un largo poema, de trece cantos, titulado "El vendedor ambulante" 12 , a su padre, un inmigrante libanés asesinado. El poema reconstruye en el vendedor a la figura emblemática del inmigrante árabe, en suelo extranjero, como producto de la diáspora y el exilio.

10 De ellos destacan los hermanos Fauzi y Shafiq Ma'aluf. La obra del primero estuvo marcada por el pesimismo y el presagio y, la del segundo, un reconocido mecenas y promotor de la Liga Andalusa, fue más amplia debido a que incluía poemarios amorosos y otros de raigambre mitológica o nacionalista. Un ejemplo de estos últimos es el poema "Árabes": "Árabes en el exilio, pueblo en dispersión / nuestro reino está más allá de las fronteras. / El día en que nos encerraron en la cárcel, / irrumpimos, pujantes, las puertas de la eternidad".

11 Obras de Asís Féres: El vendedor. Santiago de Chile: Laiazul, 1970. Michael Mason Frente. Santiago de Chile: Laiazul, 1952. Los dioses mueren lejos. Santiago de Chile: Laiazul, 1951. Al otro lado del sueño. Buenos Aires: Castiglioni, 1943. Sueños mutilados. Río de Janeiro: Apolo, 1940. Esta selección fue tomada de Mirian Namur: "Sincretismo cultural e imagens de mulher na literatura árabe-brasileira de Assis Feres e Jamil Almansur Haddad" (PDF).

12 La traducción de estas estrofas es nuestra y están tomadas de http://www.educadores. diaadia.pr.gov.br/arquivos/File/2010/artigos_teses/SOCIOLOGIA/2009/5artigoSINCRE TISMOCULTURAL.pdf 
El vendedor

y este cuadro ahora ilógico,

en el esplendor de la madrugada

vuelve a esta escena después

de llenar de vino las cabezas

con aquel hachich o arak

extraído de las parras

de aquellos racimos de uvas

condensadas en el alquibir

y menciono también las danzas árabes

toda esa gama folclórica

de "Al Homa" hasta "Mashel zah rura"

sobre aspectos suraias (que es también la toponimia de los nombres más bellos)

(Canto I, p. 68)

En los siguientes versos, el hablante lírico evoca, en la imagen de una madre con sus hijos, un amor idealizado de su pasado:

Vi a aquella dama subiendo

con sus hijitos detrás;

examiné su lindo rostro

y comprendí bastante de ella.

Nadua, belleza venusina,

uno de esos botones en el tiempo,

era la flor de la despedida

una estampa del espacio celestial...

(Canto I, p. 22)

$\mathrm{Y}$ en estos versos el hablante lírico evoca estampas y mujeres del pasado, anunciando amores imposibles, tal como ocurría en los poemas medievales de la época omeya.

Mensaje del destino

¿dónde estará la pobre alma

que vaga en un mismo tormento, 
sin que mi cuerpo le pertenezca a ella

y que aún la contemplo con la pasión de antaño?

Quiero cantarle a ella, sin palabras, quiero llorarla hasta morir de llanto!

¿Dónde estará la amada celestial de mi primer corazón en la tierra?, ¿a quién pertenece mi ser de siempre?

(Canto I, p. 113)

...

¿Dónde está la excelsa Ramza, y dónde está su tierna Zane? ¿Lamia'ah y la gran Moufide y y Obaida y Futin en el tiempo?

(Canto II)

El tema de Palestina es objeto de preocupación en algunos poetas chilenos, como en el caso de Mahfud Massís ${ }^{13}$, autoexiliado en Caracas. En el poema XVIII (Massís 1990: 146), del poemario Llanto del exiliado (1986) la voz lírica en un sentimiento angustioso y desgarrado lamento expresa el doble exilio, para mostrar a Palestina y Líbano en visiones simultáneas de soledad y muerte y el destierro del poeta de su patria. Todas ellas se funden finalmente al recuerdo de la madre, mientras el hablante lírico yace sometido y extenuado de dolor y muerte:

13 Mahfud Massís nació en Iquique, en 1916; y falleció en Caracas, en 1990. Fue hijo de padre palestino y madre libanesa. Estuvo casado con la pintora Lukó de Rokha (hija del poeta Pablo de Rokha), con quien tuvo dos hijos. Su producción literaria comprende fundamentalmente poesía y, en menor proporción, ensayo, cuento, teatro y crónica. En total dieciséis libros, de los cuales once fueron escritos y publicados en Chile; cinco durante el autoexilio del escritor en Venezuela. Entre sus obras se encuentra una edición póstuma. La producción chilena de libros es la siguiente: Litoral celeste (1940), poesía; Los tres (1944), ensayo; Los sueños de Caín, cuentos existencialistas; Walt Whitman, el visionario de Long Island, ensayo (ambos en 1953); Elegía bajo la tierra (1955), poesía; Sonatas del gallo negro (1958), prosa poética; Leyendas del Cristo negro (1963), en prosa poética; El libro de los astros apagados (1965), poesía. En Venezuela, publicó el poemario Testamento sobre la piedra (1971); El hombre y sus circunstancias (1981), crónicas; Llanto del exiliado (1986) y Este modo de morir (1988), ambos poemarios; la Antología (1990) y el poemario póstumo Papeles quemados (2001). 
La verdad, no tengo de dónde agarrarme a veces.

Pienso que estoy ciego, que todo

fue abortado

y Palestina cuelga su último muerto

en el olivar.

Y tú, Líbano

de las maderas resonantes, cómo fuiste

asolado. Mi sangre

está ahora en la viscosa boca del tiburón.

¿Y Chile? iQué piedra! Ah, ya no tengo pasado, y no puedo volver.

Mi lengua de carnicero

no puede asociarse ahora a la velocidad

de las aguas, y digo

qué pobre historia de arúspices

es esta

en que yazgo

cubierto de hojas de sueños de cáñamo y resina.

Cuando descubro mi rostro,

un transeúnte pregunta de qué prisión vengo.

Escucho una multitud, un alarido que reconozco, como reconocería un dedo

cortado, o tu propio

rostro, Madre, cuando te morías

y yo estaba en Caracas

esperando el diluvio sentado en una tinaja negra...

Mientras tanto, en Nicaragua, la poetisa, narradora de cuentos infantiles y periodista Suad Marcos Frech (Nicaragua, 1946), descendiente de inmigrantes palestinos de Belén, en parte de su escritura devela episodios autobiográficos ${ }^{14}$ como su experiencia en Medio Oriente, junto a Yaser Arafat; y por otro lado, cultiva la poesía erótica ${ }^{15}$ como respuesta transgresora al canon que le impedía representarse como persona deseante

14 Desnuda ante mi sombra (2002).

15 Para que no mueran las palabras. 
y deseada. Asimismo, también ha manifestado que tiene un compromiso político y emocional con la causa palestina. En el poema titulado "En este cementerio contando tumbas nuevas" ${ }^{16}$ canta así:

Hoy mi melancolía

ya no es un calendario sin días.

Cada tumba es un mediterráneo

que se me despierta y abre

como un golpe nostálgico.

Aquí están ahora mis manos,

que crecieron allá lejos

junto a las manos de mis muertos

cantando, bienvenidos amores viejos

en estos tiempos difíciles.

La vinculación emocional y política con la causa de Palestina y especialmente con su máximo líder, Yaser Arafat a quien conoció en un viaje $^{17}$, le inspiró este poema, con motivo de su deceso:

El día me sorprende

frente al televisor.

Anunciaron tu muerte.

Ajustada a tu silencio, coloco mis sueños

debajo de tu tumba.

Sin coronas ni oradores

te entierro a mi manera.

16 A este poema le precede el epígrafe "Después de la invasión al Líbano en 1982, a mis abuelos que emigraron a América".

17 Viajó al mundo árabe cuando integró una embajada de la Organización para la Liberación de Palestina y experimentó el ruido de las bombas, los disparos y el dolor causado por la guerra entre el ejército israelí y los palestinos. A su regreso a Nicaragua, en 1982, la nombraron "Internacionalista". Esta sobrecogedora experiencia en el Medio Oriente le inspiró su poemario Desnuda ante mi sombra (2002).

Bol. Acad. peru. leng. 54(54), 2012 
Sobre tu pecho deposito este poema.

Mientras, el Profeta sonriente, recibe al dulce terrorista en su cielo.

En el mismo derrotero, la lírica del escritor venezolano y descendiente de libaneses Tarek William Saab Halabi ${ }^{18}$, propone una poesía revolucionaria, intimista, existencial, erótica, amorosa, presagio de incertidumbres, clemente, indulgente, un juego entre la muerte y la vida, llena de anhelos libertarios y de justicia. Según su opinión, en su obra lírica ha querido mostrar el itinerario de un país expoliado y, por extensión, un continente que ha sido dramáticamente humillado por muchos colonizadores; además, ha pretendido unir, de alguna manera, el arabismo con la indianidad. El poema "Al-Fatah" ${ }^{19}$ del poemario del mismo nombre muestra dos espacios diferentes y unidos por el mar: uno paradisíaco, otro belicoso; pero en ambos existe la posibilidad de amar.

\author{
Volveremos a ser amantes bajo el Sol de Acapulco \\ o a la orilla \\ de una barricada \\ incendiada en la Franja de Gaza
}

18 Tarek William Saab Halabi nació en el año 1963. Es un político, un abogado, un reconocido activista de los derechos humanos y uno de los dirigentes y partidarios más conocidos del presidente Hugo Chávez. Fue diputado al parlamento en 1998 y miembro de la Asamblea Nacional. Actualmente es el gobernador de su estado natal, Anzoátegui. Conocido como El Poeta de la Revolución, ganador de varios premios internacionales. Ha escrito numerosas obras literarias como: Los ríos de la ira (1987), El hacha de los santos (1992), Príncipe de lluvia y duelo (1992), Al Fatah (México, 1994), Ángel caído ángel (1998), Cielo a media asta (2003), Cuando pasen las carretas (2003), Los niños del infortunio: Memorias de la misión médica cubana en Pakistán (2006), Memorias de Gulan Rubani (Caracas, 2007), Un paisaje boreal (Valencia, 2008. Caracas, 2009, en PDF).

19 Al Fatah significa "victoria a través de la Yihad" (Guerra Santa). Es una organización de resistencia palestina, fundada en 1959, en Kuwait, por Yasser Arafat quien se convirtió en el líder de la OLP (Organización para la Liberación de Palestina), en enero de 1996 hasta su muerte en 2004, en Gaza. Preconiza la lucha contra Israel y su objetivo final es la creación de un Estado árabe palestino independiente.

Véanse otros poemas de este autor en el sitio web: http://www.poeta.tarek.net.ve/Jesus Sanoja_Hernandez.html 
Sino tomaré por asalto un 747

en dirección opuesta a los horizontes

me coronarán mina terrorista

y volaremos entre el humo colorado de una explosión

así recogerían nuestros pedazos

y volveríamos a la madera

como cuerda de guitarra

hundida en el mar.

Numerosos vates descendientes de árabes tiene Colombia, entre ellos destacan Olga Chams Eljach (1922-2009), más conocida con el seudónimo de Meyra Del Mar; Raúl Gómez Jattin (1945-1997); Giovanny Quessep (1939) y Jorge García Usta (1960-2005). Este último fue nieto de un artesano de Damasco y compuso El reino errante ${ }^{20}$ (1991). Se trata de un poemario homenaje y testimonio de la errancia de los sirios libaneses y palestinos expatriados e invadidos; también es un canto al amor de las mujeres que acogieron a los recién llegados, una oda al nuevo mundo y un susurro de esperanza. En fin, una memoria colectiva, de homenaje y recuerdos, es llevada al lirismo desde el inicio de la migración para reactualizar el proceso de inserción, adaptación e integración de los emigrantes árabes en Colombia.

\section{La salida, en el camino de Damasco a Beirut (1887)}

Oye a tu padre,

oye Manzur, el fuego que divide estos orígenes.

Rauf, anda, hay otro mundo

al fondo de ese mar opulento,

montañas que se derraman,

cielos sangrados por los augures del holgorio,

tierras donde ya no cabe más soledad.

20 Otros poemarios de este autor son: Noticias desde la otra orilla (1985), El libro de las crónicas (1989), Monteadentro (1992), La tribu interior (1995). Libro de reportajes e investigación (con Alberto Salcedo): Diez juglares en su patio (1994). Otros libros: Cómo aprendió a escribir García Márquez (1994), Visitas al patio de Celia (1995), recopilación sobre la obra periodística de Héctor Rojas Herazo. 
(nos iremos mañana sin

decir nada

a nadie)

La guerra pesa ya demasiado

en estas leves sangres de alfareros.

$\mathrm{Oh}$, ascuas natales que liquidan

la fe de los limones,

el designio de los creyentes.

Rauf, alista tus ojos.

Llevaremos lo que, ahora, somos:

una maleta, cuatro cuerpos

y memorias.

Y en el poema "Declaración de amor de Clemente Spath" el hablante lírico, ahora oculto tras la máscara de un inmigrante que desea formar familia con una como él — para fortalecer los lazos tradicionales y preservar la identidad con el enlace endogámico-, en un espacio pletórico de exuberante vegetación desconocida, canta:

No sé cómo vine

a estas tierras tan anchas.

Las voces son más solas,

los cielos más ansiosos.

El verde no limita: se derrama y duele.

el río responde, a lo lejos,

por todo destino

pero la selva ya no se sabe esperanza.

Someya Báladi,

me gustan sus manos con costumbres,

su parentesco con la lluvia,

su oficio de sombra.

La veo salir y entrar a la luz 
como puñal de leyenda.

Puedo prometerle, apenas, una casa con lámparas, cinco hijos correctos, almacén y hombrías.

Usted, Someya Báladi, es mi tercera patria.

En México se distingue la figura de Jaime Sabines (1926-1999), hijo de libanés y chiapaneca. En su poética sobresale el tema de la muerte que brota de la absoluta certeza de que el hombre experimenta la soledad desde sus orígenes, cuando percibió la pérdida de Dios. En virtud de este sentimiento de orfandad y desesperanza, para este poeta el hombre no tiene otra opción que vivir el presente, el aquí y el ahora, en un derrotero de aprendizaje que lo acerca al otro, para buscar respuestas que no ha encontrado en ese Dios silencioso y ausente. Se puede afirmar, entonces, que su palabra poética es un revelarse para exhibir su confesión, porque, desde un comienzo, se sintió un poeta condenado a morir. En este sentido - y siguiendo el pensamiento de Gilles Deleuze - planteamos que el tema de la muerte organiza una red de impronta rizomática (Deleuze y Guatarri 1997) en la poesía sabineana. Así, la muerte de su progenitor, en 1961, deviene en arte en la elegía Algo sobre la muerte del mayor Sabines. En esta obra describe la soledad de su padre, don Julio, un libanés emigrado que alcanzó el grado de mayor en el ejército del general Carranza, durante la revolución mexicana, el cual yace enfermo en viaje a su destino final. Como Antara, el héroe preislámico, don Julio se destacó por su fiereza en el combate, su fidelidad, dedicación, generosidad y amor hacia la familia. De esta manera, Jaime Sabines reactualiza la murua árabe - $\mathrm{O}$ el conjunto de cualidades que destacan a un hombre - cuando recuerda amorosamente a su padre, convocándolo del pasado como una búsqueda ontológica del ser, anhelando derrotar su muerte física, en un acto extremo de desesperación y rebelión, ante la inadmisible e irremediable presencia de la muerte.

(...) Tú eres el tronco invulnerable y nosotros las ramas, por eso es que este hachazo nos sacude.

Bol. Acad. peru. leng. 54(54), 2012 
Nunca frente a tu muerte nos paramos

a pensar en la muerte,

ni te hemos visto nunca sino como la fuerza y la alegría.

(...) no ha habido hora más larga que cuando no dormías,

ni túnel más espeso de horror y de miseria

que el que llenaban tus lamentos, tu pobre cuerpo herido.

(...) Y mientras tú, el fuerte, el generoso,

el limpio de mentiras e infamias,

guerrero de la paz, juez de victorias

— cedro de Líbano, robledal de Chiapas-

te ocultas en la tierra, te remontas

a tu raíz oscura y desolada ${ }^{21}$.

En la poesía neomahyarí cultivada en Centro América descuella, por ejemplo, el vate y antologador Osvaldo Sauma ${ }^{22}$ (1949), nacido en Costa Rica. En su poema "Raíces" valora la cultura ancestral, de raigambre preislámica:

\section{La poesía es el oro de los árabes}

(G. Virgil Georghiu)

Mis detractores ignoran

que la memoria espía

el itinerario de los abuelos

no advierten

que el esplendor de los desiertos

impide que me arrebaten

el oro de los versos

y la fuerza de la sangre

21 "Algo sobre la muerte del mayor Sabines" (SABINES 2005: 404).

22 Publica a partir de 1980, mientras se dedica a la docencia en el Conservatorio de Castella y a antologar textos con diversas tendencias o temáticas, por lo que su labor ha influenciado a escritores jóvenes de la siguiente generación. También ha participado en varios festivales internacionales de poesía. Entre sus poemarios están: Las huellas del desencanto (1982); Retrato de familia (Premio Latinoamericano de Poesía Educa, 1985); El aire habitado (1992); Asabis (1993); Madre nuestra, fértil tierra (1997); Bitácora del iluso (2000); El libro del adiós (2006). 
inútiles resultarán

sus maledicencias

esta raíz ancestral

me entrelaza

a la legendaria feria de Ukaz

en el tiempo de la Tregua de Dios

donde los poemas victoriosos

se transcribían en seda negra

y un año duraban

proclamando entre los vientos

la tesitura del más noble de los árabes:

el que bajaba la hija del ojo al corazón

o esculpía una flor entre los labios.

El tema del legado de Al Andalus, la nostalgia de la gloria pasada, los amigos muertos, el futuro vacío de poder y tiempo debido a su pérdida irreparable, se observa en el poema "El rey moro" del vate colombiano Raúl Gómez Jattin ${ }^{23}$.

No volverá a ver la Alhambra en su esplendor

de jardines y palacios

donde canta el agua.

Los años de mirar la luna del poniente,

oyendo los poetas leer sus versos

y escuchando el laúd

huyeron de su vida como asustados pájaros.

Nadie — lo sabe íntimamente- lo devolverá

al Califato de Córdoba su ciudad amada.

Nadie - y llora mirando la costa lejana

que se desdibuja en el horizonte.

23 Raúl Gómez Jattin (1945-1997) es autor de los siguientes libros: Conjuro (1957-), Poemas (1981), Retratos (1980-1989), Amanecer en el valle del Sinú (1983-1989), Del Amor (19821987), Hijos del tiempo (1989), Esplendor de la mariposa (1993), Los poetas, amor mío... (2000, libro póstumo). "El rey moro" pertenece al poemario Hijos del tiempo. Una síntesis de su azarosa existencia se puede ver, entre otras publicaciones, en http://www.arquitrave.com/ poetas/Raul_Gomez_Jattin/Raul_Gomez_Jattin.htm

Bol. Acad. peru. leng. 54(54), 2012 
Nadie regresará a los amigos que murieron.

Ahora al desierto áspero de Túnez o Marruecos

o a las montañas de Líbano o de Siria.

Tantos siglos construyendo pueblos y ciudades, irrigando llanuras

cultivando frutales

enseñando la Alquimia y el Álgebra

la Poética, la Astronomía y la Música

$Y$ todo se ha perdido en unos cuantos años.

En unas pocas batallas todo se esfumó

como un espejismo en medio del Sahara.

Presentar a estos vates, hijos de la inmigración árabe en América Latina, significa establecer un espacio en el canon de los estudios de la literatura de sus respectivos países. La poesía neomahyarí puede ser considerada una variedad de literatura intercultural, cultivada por los descendientes de los inmigrantes árabes y que interactúa con la cultura local, siguiendo los modelos escriturales de la tradición canónica, por lo tanto, contribuye, a través del cultivo del tema de la nostalgia, el pensamiento y la libertad, a dar a conocer una determinada realidad, tanto la de los pioneros como la de los descendientes árabes en la región. Ellos recuerdan y preservan la tradición, testimonian los avatares de la migración de los expatriados, evidencian y cantan al espacio de acogida y denuncian el drama que vive un pueblo que clama por su libertad. 


\section{BIBLIOGRAFÍA}

AGAR, Lorenzo

1977

"La inmigración árabe en Chile: los caminos de la integración”. En: El mundo árabe y América Latina. Madrid: UNESCO/Libertarias/Prodhufi, 283-309.

2009 Contribuciones árabes a las identidades iberoamericanas. Madrid: Casa-Árabe-IEAM.

AKMIR, Abdeluahed (coord.)

2009 Los árabes en América Latina. Historia de una emigración. Madrid: Siglo XXI de España Editores y Casa-Árabe e Instituto Internacional de Estudios Árabes y del Mundo Musulmán.

BAHAJIN, Said

El modelo latinoamericano en la integración de los inmigrantes árabes (PDF).

DELEUZE, Gilles y GUATTARI, Félix

1977 Rizoma. Valencia: Talleres Gráficos Ripoll S. A.

GARCÍA USTA, Jorge

1991 El reino errante: poemas de la migración y el mundo árabes. Cartagena: Litografía Jonan.

GOIĆ, Čedomil

1972 Historia de la novela latinoamericana. Valparaíso: Universitarias de Valparaíso.

MACÍAS, Sergio

1995 Presencia árabe en la literatura latinoamericana. Santiago de Chile: Universitaria.

MAKKI, Mahmud

La prensa árabe en América Latina (PDF).

Bol. Acad. peru. leng. 54(54), 2012 


\section{MARTÍNEZ LILLO, Rosa}

1994 Cuatro autores de la Liga Literaria. Madrid: CantArabia y el Departamento de Estudios Árabes e Islámicos de la Universidad Autónoma de Madrid.

\section{MARTÍNEZ MONTÁVEZ, Pedro}

1974

Introducción a la literatura árabe moderna. Madrid: Almenara.

MASSÍS, Mahfud

1990 Antología. Poemas (1942-1988). Venezuela: Dialit.

RAFIDE, Matías

1989 Escritores chilenos de origen árabe. Santiago de Chile: Instituto Chileno-Árabe de Cultura Universitaria.

REBOLLEDO, Antonia

1994 "La 'turcofobia': discriminación antiárabe en Chile, 19001950”. En Historia. 28, Santiago, 249-272.

SABINES, Jaime

2005

Antología poética. México: Fondo de Cultura Económica.

SAMAMÉ, María Olga

2009 "Construcción de una poética antisolar en Mahfud Massís". En Revista Chilena de Literatura, 75, 129-156.

2006 "La poesía del Mahyar o de la emigración árabe a Chile y a Colombia, a través de los poetas Mahfud Massís y Jorge García Ustá”. En Taller de Letras 39, 9-24. Literatura de origen árabe en América Latina. www.hostos. cuny.edu/oaa/pdf/lawi/Article20Apr7 


\section{Correspondencia:}

María Olga Samamé B.

Docente del Centro de Estudios Árabes de la Universidad de Chile.

Correo electrónico: msamame7@gmail.com 